\title{
La conducta comunicativa de los niños autistas en situaciones naturales de interacción
}

\author{
RiCARDO CANAL \\ Universidad de Salamanca \\ ANGEL RIVIÈRE \\ Universidad Autónoma de Madrid
}

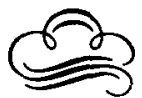

Resumen

En este trabajo se revisan las investigaciones recientes sobre el problema comunicativo preverbal de los niños autistas. Después se realiza un estudio empirico comparativo de las relaciones de contingencia entre pautas comunicativas y expresivas adultas, y conductas comunicativas prelingüísticas de niños autistas, normales y sindrome de Down, menores de 24 meses de EM.

Para estudiar las interacciones madre-niño se usó el Análisis Secuencial de Retardo (Sackett, 1980) que, hasta ahora, no se habia aplicado al estudio descriptivo de las peculiaridades interactivas de los niños autistas.

Los resultados indican que los niños autistas, además de carecer de declarativos, mostraban déficits en actos imperativos, y en su respuesta a expresiones emocionales positivas del adulto. Los datos son favorables a la bipótesis de que los autistas sufren un problema en las habilidades comunicativas precursoras de la capacidad metarrepresentacional.

Palabras clave: Autismo, interacción, comunicación prelingüística, expresiones emocionales, funciones comunicativas, atención conjunta, metarrepresentación.

\section{Abstract}

In this study recent research on the prelinguistic communicative problems of autistic children was reviewed, Next, a comparative empirical study of contingency relations was made. We analysed the contingency relations among communicative and expressive acts shown by an adult, and prelinguistic communicative bebaviour shown by autistic, nomal, and Down sindrome children, under age 24 months $M E$.

The study of mother-infant interactions was made using the Lag Secuential Analisis (Sackett, 1980) which, to date, bad not been used to analyse interactive characteristics of autistic children.

Results indicate that autistic children, in addition to a lack of declarative acts, showed deficits in the imperative function, and also in their response to positive emotional expressions displayed by the adult. Our data support the bypothesis that autistic cbildren bave problems in communicative skills which bave been considerated precurson to the metarrepresentational capacity.

Key words: Autism, interaction, prelinguistic communication, emotional expressions, communicative functions, joint atention, metarrepresentation.

Dirección de los autores: Universidad de Salamanca. Facultad de Psicología. Avda. de la Merced, 109-131. 37005 Salamanca.

Universidad Autónoma de Madrid. Facultad de Psicología, Dpto. de Psicología Básica. Ctra. de Colmenar Viejo, km 15 (Cantoblanco). 28049 Madrid 
El estudio del problema comunicativo en los niños autistas: Una cuestión abierta

Las anormalidades en la comunicación no verbal son una característica destacada de los niños autistas; $y$ han sido estudiadas por un gran número de investigadores. Desde los primeros estudios se subraya la importancia de algunos problemas comunicativos para definir la naturaleza del autismo, como por ejemplo la inadecuación de las expresiones emocionales, o la ausencia y singularidad de gestos expresivos (Kanner, 1943). Aunque hubo algún estudio previo, fue a finales de los años 70 cuando se empezó a precisar en la extensión de los problemas comunicativos de los niños autistas no verbales. Una de las investigaciones más relevantes puede ser la de Curcio (1978), quien informó que los niños autistas de su estudio no mostraban gestos con función protodeclarativa y sí gestos con función protoimperativa. Más tarde, Wetherby y Prutting (1984) encontraron en un estudio con cuatro niños autistas que éstos usaban conductas comunicativas peculiares para conseguir objetos, acciones y juegos sociales simples pero no gestos para indicar simplemente, o para compartir un conocimiento sobre un objeto con otras personas. Otros estudios posteriores (Loveland y Landry, 1986; Mundy, Sigman, Ungerer y Sherman, 1986), empezaban a sugerir que esa peculiaridad en el repertorio comunicativo de los niños autistas podría ser específica del síndrome de autismo. Por ejemplo, Loveland y Landry (1986) encontraron que los niños autistas de su estudio, comparados con niños normales y niños con retraso en el desarrollo del lenguaje, mostraban menos conductas gestuales con función declarativa y respondían menos a adultos que iniciaban actos declarativos.

Si bien estos primeros estudios sugerían, desde planteamientos distintos, que el problema comunicativo principal de los niños autistas no verbales es la ausencia de habilidades comunicativas con función declarativa ninguno podía asegurar que dicho déficit fuera específico del autismo, ya que en todos ellos había niños autistas que también eran deficientes mentales, y el problema comunicativo que mostraban podría ser consecuencia de su bajo funcionamiento cognitivo. Fueron Mundy, Sigman, Ungerer y Sherman (1986) quienes, teniendo en cuenta este hecho, probaron que los problemas en habilidades declarativas mostrados por los niños autistas servían para discriminar a este tipo de niños de los deficientes mentales. También probaron que los problemas no sólo consistían en la ausencia de actos declarativos, sino que además los autistas carecían de otras habilidades de atención conjunta ${ }^{1}$ (i.e. de otras habilidades para coordinar la atención entre los participantes de una interacción con la intención de compartir una experiencia sobre objetos o eventos) como el caso de la mirada referencial. En ese fructífero estudio de 1986, Mundy y sus colaboradores concluyeron también que el problema comunicativo no podría deberse a dificultades en la estrategia para organizar un despliegue atencional triádico con fines comunicativos (Bakeman y Adamson, 1984), necesario para compartir la atención entre uno mismo, otro y un objeto o evento. Dicha estrategia no es exclusiva de los actos comunicativos que tienen función declarativa, sino que los actos comunicativos tienen función imperativa requieren igualmente tal tipo de despliegue atencional, y los niños autistas parecen capaces de ejecutarlos. Sin embargo, los resultados de un reciente estudio (Phillips, Laa, Gómez, Rivière y Baron-Cohen, en prensa) sugieren que en los niños autistas no verbales existen deficiencias en la organización del despliegue atencional, aún con fines comunicativos de tipo imperativo. 
Siguiendo con Mundy et al. (1986), la respuesta a por qué los niños autistas no muestran actos declarativos es también la respuesta a cuál es la naturaleza del déficit que sufren estos niños. Partiendo de una perspectiva cognitivo-social, estos autores consideran que los actos declarativos son distintos de los actos imperativos, en tanto que los primeros marcan el desarrollo del conocimiento en el niño de que los demás pueden atender e interesarse por lo que le interesa al propio niño. Este conocimiento de que los demás pueden ser «agentes de contemplación» (Werner y Kaplan, 1963) estaría ausente o sería deficitario en los autistas. Por eso, estos niños no muestran conductas de atención conjunta con otra persona con la única intención de compartir una experiencia sobre un objeto o evento. Según estos autores, tal carencia impediría que los niños autistas llegaran a entender que los otros tienen estados mentales propios como el interés por los objetos, y podría estar relacionada con el déficit en el contacto afectivoempático descrito inicialmente por Kanner (1943).

La existencia en los niños autistas de un problema para entender que los otros tienen estados mentales propios, más concretamente, la presencia de un problema en la capacidad para atribuir estados mentales de falsa creencia ${ }^{2}$ a los demás, ha sido ampliamente probada (Baron-Cohen, Leslie y Frith, 1985, 1986; Baron-Cohen, 1989a), así como la influencia de ese déficit en el problema comunicativo de los niños y adolescentes autistas (Attwood, Frith y Hermelin, 1988; Perner, Frith, Leslie y Leekam, 1989; Baron-Cohen, 1989b). Todos estos autores tienen la idea común de que los niños autistas nacen con algún tipo de alteración biológica, que impide o dificulta el desarrollo de la capacidad metarrepresentacional, y que esto supondría un déficit cognitivo específico que explicaría, del modo más fácil, los problemas comunicativos y simbólicos de los niños autistas. Además, estos autores postulan con su hipótesis que los niños autistas mostrarán un perfil de habilidades comunicativas peculiar: sólo se observarán problemas en aquellas habilidades comunicativas que impliquen necesariamente el uso de la capacidad metarrepresentacional (Frith, 1989). Sin embargo, se considera que la manifestación más temprana de la capacidad metarrepresentacional aparece a lo largo del segundo año de vida, cuando el niño realiza actividades de juego simbólico (Leslie, 1987). Meses después de que haya aprendido a utilizar procedimientos comunicativos, no simbólicos, con la intención de compartir una experiencia. En otras palabras: si la capacidad para atribuir estados mentales no está presente en el repertorio de los niños normales al menos hasta el inicio del segundo año de vida, dicen Mundy y Sigman (en prensa), los problemas en atención conjunta de los niños autistas no pueden estar causados por un problema en tal capacidad, ya que las habilidades en las que los niños autistas muestran problemas aparecen normalmente antes de que aparezcan las habilidades de juego simbólico. Por tanto, el déficit metarrepresentacional no puede ser el causante del déficit en atención conjunta. Mundy y Sigman (en prensa) llegan a la conclusión de que los problemas en habilidades no verbales de atención conjunta pueden contemplarse como una manifestación importante y característica de aspectos tempranos del proceso de desarrollo autista, que no están directamente causados por un déficit de tipo simbólico o metarrepresentacional.

Una idea que se ha sugerido para resolver esta cuestión es que las habilidades no verbales de atención conjunta sean manifestaciones previas relacionadas con el desarrollo posterior de la capacidad metarrepresentacional. Esta idea, propuesta en los trabajos de Baron-Cohen (1989b) y Leslie y Happé (1989), no está 
suficientemente elaborada, aunque resulte intuitivamente atractiva. Plantea que algunas habilidades de atención conjunta, en concreto los actos protodeclarativos, podrían ser considerados precursores de la capacidad metarrepresentacional. Serían habilidades más simples y tempranas que se asociarían al desarrollo subsecuente de tal capacidad, pero que por sí mismas no implicarían metarrepresentación (Baron-Cohen, 1989b). Los actos comunicativos que se basan en habilidades precursoras incluirían sólo mecanismos sensibles a señales sociales y comportamentales del otro (Leslie y Happé, 1989) —orientación de la mirada, expresión emocional, postura corporal, etc- - directamente percibidas. Esos mecanismos primarios permitirían al niño organizar intencionalmente la acción interactiva, captando la atención del otro hacia uno mismo, para mostrarle la intención de que atienda a algo que se desea compartir, mostrar, obtener, etc. Baron-Cohen (1989b) sugiere que el predicado de esas acciones es «quiero que atiendas a lo que yo atiendo». Cuando ese algo hacia lo que el niño quiere que el otro atienda no es un objeto o evento directamente percibido, sino una representación de otra cosa, por ejemplo, cuando un niño llama la atención del adulto al tiempo que hace como si bebiera de una forma geométrica hueca, y después espera sonriente una respuesta mirando al adulto, ese acto comunicativo de niño ya no es un precursor de la capacidad metarrepresentacional, sino que es un acto que requiere totalmente su uso. El predicado sería «quiero que atiendas a lo que yo pienso». El niño habrá utilizado mecanismos que procesan señales sociales y comportamentales primarias para controlar y dirigir la atención del adulto, pero además, ha incorporado un proceso de metarrepresentación para compartir no una experiencia perceptiva, sino una experiencia mental.

La idea de definir y estudiar habilidades precursoras de la capacidad metarrepresentacional es de gran interés para el estudio de los problemas comunicativos de los niños autistas, y podría ayudar a establecer cómo el déficit inicial en atención conjunta se relaciona con el déficit cognitivo posterior. Pero, a excepción de los actos protodeclarativos y la mirada referencial, no se han descrito otras habilidades comunicativas de atención gestual conjunta sólo sensibles a señales sociales y comportamentales que también estén alteradas en estos niños. Este hecho puede que se deba a dos razones fundamentales, a saber: (1) la edad mental de los sujetos autistas estudiados en todas las investigaciones precedentes es siempre superior a los dos años, por lo que analizan niveles de edad en los que pueden haberse superado o compensado los posibles problemas en habilidades precursoras; y (2) los investigadores que han proporcionado la idea de las habilidades precursoras defienden una hipótesis estrictamente cognitiva, que intenta explicar el problema comunicativo de los niños autistas ignorando, parcialmente, la importancia del componente emocional que acompaña a todo acto comunicativo.

Los estudios sobre el desarrollo comunicativo y social de los niños pequeños normales destacan que el funcionamiento cognitivo, social y afectivo está indisolublemente unido (Trevarthen, 1982; Schaffer, 1984), y que el propio desarrollo comunicativo y simbólico puede estar sujeto a factores sociomotivacionales, que permitan un alto grado de desarrollo de habilidades intersubjetivas (Rivière, 1990). Parece que el desarrollo simbólico en general requiere, además de cierto nivel de desarrollo comunicativo y cognitivo, que el niño haya compartido experiencias emocionales con los otros. Es decir, que haya pasado por una fase inicial de «intersubjetividad primaria», en la que el niño, aún no reconociendo el valor de señal de las expresiones emocionales de los demás, respon- 
de a tales expresiones emocionales con actos de la misma naturaleza. Actos que los adultos interpretarán, desde el principio, como intencionalmente significativos de un estado emocional, y a los que no sólo responderán imitándolos, sino también dándoles contenido por medio de otros actos comunicativos. $\mathrm{Al}$ parecer, sólo después de que el niño alcanza esa experiencia intersubjetiva primaria, de carácter emocional, donde las expresiones del niño dependen de las de su madre, y viceversa, se puede acceder al nivel en el que el niño usa intencionalmente sus expresiones emocionales con intención comunicativa (Rivière, 1990).

También para Mundy y Sigman (1989) el intercambio afectivo que forma parte del sistema comportamental en el que se ejecutan los actos comunicativos es un aspecto importante de las habilidades de atención conjunta. Cuando los niños normales comparten su atención con otro sobre un objeto o evento, comparten al mismo tiempo un estado afectivo sobre dicho objeto o evento. Su hipótesis general postula la idea de que los niños autistas no tienen una experiencia afectiva normal en la interacción con los demás porque las señales sociales y comportamentales que provienen del otro producen una activación emocional atípica en estos niños, que les lleva a una comprensión empobrecida del valor del afecto como señal.

Sin embargo, la evidencia empírica de una alteración en la sensibilidad afectiva es aún pequeña (Leslie y Frith, 1990), sobre todo en sujetos autistas que no alcanzan una edad mental superior a los dos años. Pero, aunque sean pocos los investigadores que se han centrado en el análisis de las dificultades de los niños autistas en procesar señales emocionales, y menos aún los que hayan hecho un estudio de la influencia de estos problemas en el desarrollo temprano de habilidades comunicativas, la evidencia es prometedora. Por un lado, los niños autistas muestran un patrón característico en los procesos de atención e interpretación de señales emocionales, como lo prueban los trabajos de Hobson y colaboradores (Hobson, 1986a, 1986b; Hobson, Outson y Lee, 1988a, 1988b) que sirvieron para demostrar que los niños y adolescentes autistas tienen problemas en la asociación intermodal de señales socio-emocionales. Por otro lado, los recientes trabajos de Yirmiya, Kasari, Sigman y Mundy (1989) y de Kasari, Sigman, Mundy y Yirmiya (en prensa) proporcionan alguna evidencia de que los niños autistas muestran un patrón característico en la expresión de afecto cuando realizan actos comunicativos, ya que las escasas ocasiones en que los autistas de sus estudios mostraban conductas de atención conjunta, éstas iban acompañadas de expresiones neutras o confusas de afecto por parte del niño, al contrario que los niños de los grupos de control que mostraban afecto positivo cuando realizaban actos de atención conjunta.

Estos datos estarían en consonancia con la hipótesis general de Mundy y Sigman (1989). Pero se hace necesario replicar y ampliar esos estudios antes de establecer conclusiones definitivas. Lo que esos estudios sugieren es la necesidad de considerar la existencia de factores socio-afectivos, y no sólo los sociocognitivos, para comprender la extensión de los problemas en comunicación no verbal de los niños autistas. Sin embargo, definir las habilidades socioemocionales para la comunicación sólo en términos de su frecuencia y duración, como índice de la alteración, puede no llevar a una explicación suficiente de la alteración social y comunicativa de los niños autistas respecto de otros grupos de niños (Canal, 1991). Los métodos de la psicología evolutiva que han demostrado la importancia de las habilidades intersubjetivas se basan en el análisis de secuencias interactivas, reconociendo la influencia mutua entre los distintos 


\section{4}

elementos de una interacción (Cf. Trevarthen, 1982; Bakeman y Adamson, 1984; Schaffer, 1984), lo que hasta ahora no había sido hecho en ningún estudio sobre el autismo.

\section{Un estudio empírico para encontrar precursores de la capacidad metarrepresentacional}

$\mathrm{El}$ análisis que acabamos de exponer nos plantea un reto muy interesante: investigar si existen habilidades comunicativas preverbales que podrían ser precursoras de la capacidad metarrepresentacional. Esa investigación debería analizar la estrategia que realiza el niño para controlar y dirigir la atención del adulto, ya que, como hemos dicho, las habilidades precursoras se organizan en una estrategia de control de la atención del interlocutor. El estudio de esa estrategia debería permitirnos diferenciar qué habilidades comunicativas no verbales nos hacen esperar que el niño va a desarrollar en el futuro conceptos de estados mentales. En otras palabras: queremos saber cuándo la estrategia comunicativa contiene una «semilla mentalista» de la que crecerá la capacidad para compartir estados mentales sobre los objetos o eventos. Esperamos que ese estudio diferencie a los niños autistas de otros grupos de niños, de modo que, por un lado, de acuerdo a la hipótesis cognitiva, el estudio mostraría que dichas habilidades precursoras sólo estarían alteradas o ausentes en los niños autistas. Por otro lado, siguiendo a Mundy y colaboradores, ese estudio contribuiría a aclarar la relevancia de los factores socio-afectivos en el trastorno del desarrollo de la comunicación no verbal de los niños autistas.

Creemos que el procedimiento de estudio más adecuado debe basarse no sólo en diferenciar qué tipo de intenciones comunicativas son capaces de manifestar los niños autistas no verbales, sino especialmente en considerar el valor funcional de la estrategia comunicativa para manifestar intenciones, o para compartir experiencias con los demás. Esta consideración nos lleva a plantear un análisis de secuencias interactivas que implique asumir que las acciones comunicativas o sociales de cada miembro de la situación se observen conjuntamente con las del otro, coordinadas de tal modo que ambas se consideren como una entidad única, dirigida a conseguir cierta regulación mutua. No nos interesa cuántas veces, o durante cuánto tiempo, un miembro de una interacción realiza una conducta, aunque esté definida funcionalmente. Nos interesa saber en base a qué actos previos del otro el sujeto realiza esa conducta, cuya definición funcional incluye la intención para la que objetivamente sirve. Dicho de otro modo: queremos ver el impacto, y la conducta subsecuente, que una acción realizada con una intención previa por uno de los miembros de la interacción provoca en el otro y viceversa.

El estudio que pretendemos realizar debe describir, entonces, la función de las conductas componentes de estrategias ejecutadas con distintas intenciones comunicativas: imperativa, declarativa, y de regular la interacción social y el juego. Se deben definir conductas componentes de este tipo de acciones relativas a la mirada, la acción gestual y la expresión emocional, tratando de aclarar la relevancia de esos componentes para alcanzar la intención del acto comunicativo. 


\section{PROCEDIMIENTO}

\section{Sujetos}

Los sujetos estudiados fueron 18, 6 normales, 6 deficientes mentales síndrome de Down y 6 autistas. Los autistas fueron seleccionados de varios centros de educación especial donde ya habían sido diagnosticados como tales, por otros psicólogos y psiquiatras. Por tanto, todos ellos reunían los criterios que especifica la DSM IIIR (A.P.A. 1987). Es decir, incapacidad cualitativamente diferente en la interacción social recíproca, incapacidad cualitativamente diferente en el desarrollo de la comunicación, repertorio llamativamente limitado de intereses y comienzo de los síntomas antes de los 36 meses de edad cronológica. Todos los sujetos autistas tenían una edad mental inferior a los 22 meses y superior a los 13 meses, según la Escala para medir el Desarrollo Psicomotor de la Primera Infancia, de Brunet Lézine, y ninguno de ellos había desarrollado lenguaje oral ni gestual. Tanto los Down como los normales fueron igualados uno a uno en edad mental con los autistas de acuerdo a la misma escala (Tabla I).

\section{Situación}

Se diseñó una situación semiestructurada interactiva, entre el niño y su madre, que no varió en ningún caso. La madre y el niño se encontraban en una sala conocida por ambos, sentados uno frente a otro, con una mesa entre los dos (mesa 2). A la derecha de la madre (izquierda del niño) había otra mesa a la que ambos participantes alcanzaban (mesa 1). Detrás de la madre y a su derecha había una tercera mesa, más alta, donde originariamente estaban depositados los objetos y juguetes, a la vista del niño, pero fuera de su alcance. Fue imposible que todos los niños dispusieran de los mismos juguetes, pero se mantuvo el criterio de que siempre fueran seis juguetes/objetos que el niño conociera. En todos los casos hubo un juguete mecánico, un animal de juguete,

TABLA I

Caracteristicas de los sujetos

\begin{tabular}{|c|c|c|c|}
\hline Sujetos & $\begin{array}{l}\text { Normales } \\
n=6\end{array}$ & $\begin{array}{l}\text { Autistas } \\
n=6\end{array}$ & $\begin{array}{l}\text { S. de Down } \\
n=6\end{array}$ \\
\hline $\begin{array}{r}\text { E. Mental * } \\
\text { Sujeto N. }{ }^{\circ} 1 \\
2 \\
3 \\
4 \\
5 \\
6\end{array}$ & $\begin{array}{l}13,04 \\
17,09 \\
18 \\
21 \\
21,02 \\
21,11\end{array}$ & $\begin{array}{l}13,21 \\
17,12 \\
18,09 \\
21,03 \\
21,06 \\
21,18\end{array}$ & $\begin{array}{l}13,06 \\
15,15 \\
18,06 \\
21,02 \\
21,06 \\
21,15\end{array}$ \\
\hline $\begin{array}{l}\text { Media E.M. } \\
\text { D. Típica }\end{array}$ & $\begin{array}{r}18,19 \\
3,20\end{array}$ & $\begin{array}{r}18,26 \\
3,11\end{array}$ & $\begin{array}{r}18,23 \\
3,50\end{array}$ \\
\hline $\begin{array}{l}\text { Med. E. Cronológ. } \\
\text { D. Típica } \\
\text { N. }{ }^{\circ} \text { de Varones }\end{array}$ & $\begin{array}{l}1,54 \\
1,78 \\
5\end{array}$ & $\begin{array}{l}8,18 \\
0,27 \\
5\end{array}$ & $\begin{array}{l}2,46 \\
0,90 \\
5\end{array}$ \\
\hline
\end{tabular}

* Según la Escala de Brunet Lézine 
un balón o globo, un coche, cuentos o imágenes y un objeto de la vida cotidiana (ver Figura 1).

Para facilitar la posterior codificación de los datos, se colocó un espejo al lado contrario de la cámara de tal forma que permitiera ver los rostros de ambos participantes. Asimismo, se introdujo un cronómetro digital en la señal de vídeo, en la esquina superior derecha de la pantalla, para poder registrar el momento de aparición de cada conducta en cada participante, con una precisión de minutos, segundos y décimas de segundo.

\section{Figura 1}

Esquema de la situación de grabación

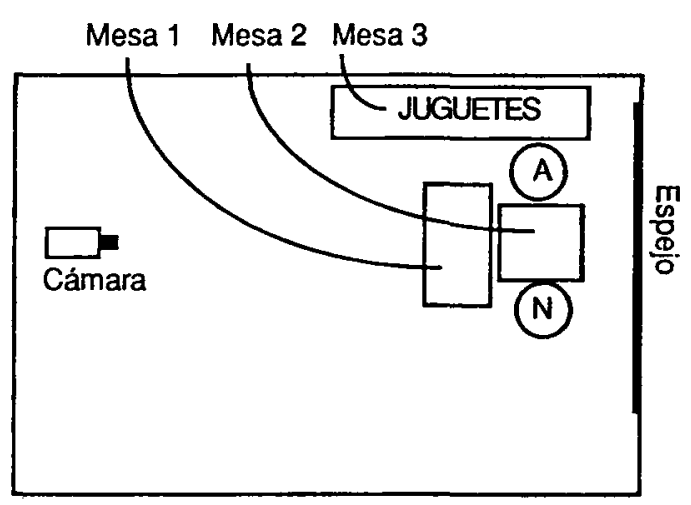

A la madre se le decía que tenía que jugar con su hijo durante 15 minutos. Debía empezar con actividades o juegos sin usar los juguetes que tenía a su disposición, esperando a que el niño espontáneamente hiciera referencia a ellos. Después de un rato (unos 5 minutos), si el niño no le había pedido ni señalado ningún objeto, ella debía ir sucesivamente mostrándoselos y usándolos para jugar con él un rato. Al terminar el juego, y antes de mostrar un nuevo juguete, debía depositar el anterior en la mesa 1 . También se le decía que en todo caso ella era libre de usar los juguetes cuando y como quisiera, y si creía que el niño le había pedido o mostrado un juguete podía dárselo o jugar con ese objeto incluso nada más empezar, o aunque ya estuviera en la mesa 1 , si ella lo juzgaba conveniente. Finalmente se le decía que no podía hablar al operador de cámara durante la grabación. Sin embargo esto ocurrió en un caso.

Las situaciones se grabaron con una videocámara marca Panasonic Mod. M-5 por un operador de cámara, que también estaba dentro de la habitación. El operador tenía instrucciones para no moverse de donde estaba la cámara, no hablar y no sacar su cara de detrás de la cámara en ningún momento. Los movimientos del operador estaban limitados exclusivamente a los imprescindibles para hacer funcionar la cámara y poner en marcha el cronómetro del tiempo de grabación. El operador no habló en ningún caso.

\section{Codificación de los datos}

Se codificaron 10 minutos de cada pareja madre-niño, dejando de registrar los dos minutos y medio del principio, y los dos y medio del final aproximadamente, porque queríamos observar una interacción madre-hijo en curso. 
Dos observadores entrenados codificaron la información en una sola hoja de registro diseñada al efecto. En esa hoja se anotaba, en cada línea, a lo largo del tiempo, cada cambio en la posición del objeto de referencia, la conducta del adulto, la conducta del niño y el tiempo que marcaba el cronómetro. El procedimiento para anotar cada conducta consistió en ver cada secuencia del vídeo tantas veces como cada observador considerase necesario, y anotar, previo acuerdo, la modificación observada (Anguera, 1988).

\section{Medidas}

Cada elemento de la situación (madre, niño y objetos) constituye un subsistema, y cada categoría de conducta definida para la madre, el niño o los objetos es considerada una unidad de conducta o estado en el que se puede encontrar ese subsistema en un momento dado.

Las categorías de conducta se definieron de modo que fueran medidas interactivas (la definición de todas ellas se realizó en términos de intencionalidad, y reflejaba la función que cumple esa conducta para la acción interactiva del sujeto). Las categorías de conducta usadas para cada subsistema también fueron definidas de modo que fueran exhaustivas y mutuamente excluyentes. Así, cada conducta ocurría, o no ocurría, en un momento determinado y ello impedía, o permitía, la presencia de las restantes. La definición que se proporcionó a los observadores incluyó parámetros observables, así como ejemplos y contra ejemplos.

Las categorías fueron clasificadas de acuerdo a los siguientes grupos: Actos para la función declarativa, actos para la función imperativa, actos para la función de regular la interacción social, actos de juego con objetos, expresiones socioemocionales y conductas no comunicativas para adaptarse a la situación interactiva (ver Tabla II).

\section{Análisis de datos}

Sobre los datos obtenidos en la codificación se aplicó la metodología del Análisis Secuencial de Retardo (ASR) desarrollada por Sackett $(1978,1980)$ y Anguera (1985) teniendo en cuenta los presupuestos metodológicos para aplicarle al análisis interactivo, que propone Quera (1986).

Elegimos el ASR por su utilidad para la descripción de secuencias de conducta mostradas por distintos sujetos, que actúan al mismo tiempo y en el mismo lugar. Con este método podemos obtener información de la probabilidad de que una conducta de un sujeto aparezca, o no, en función de la presencia o ausencia previa de otra conducta de otros sujetos o subsistemas. En este sentido, el ASR puede considerarse como un medio de obtener medidas sobre la influencia mutua existente entre varios subsistemas (sujetos y/o contextos) que interactúan. El método parte de la obtención de frecuencias de apareo a lo largo de $\mathrm{k}$ retardos (unidades de tiempo en nuestro caso), entre una conducta toma como criterio y las restantes conductas del subsistema o subsistemas estudiados, tomados como conductas o subsistemas apareados. Estas freçuencias sirven de base para obtener probabilidades de retardo, que son transformables en puntuaciones $Z$, las cuales son índices normalizados de la contingencia entre la conducta criterio y las restantes conductas apareadas a lo largo del tiempo. Dichas puntuaciones pueden sintetizarse aún más mediante los indicadores glo- 


\section{8}

TABLA II

Subsistemas de categorías

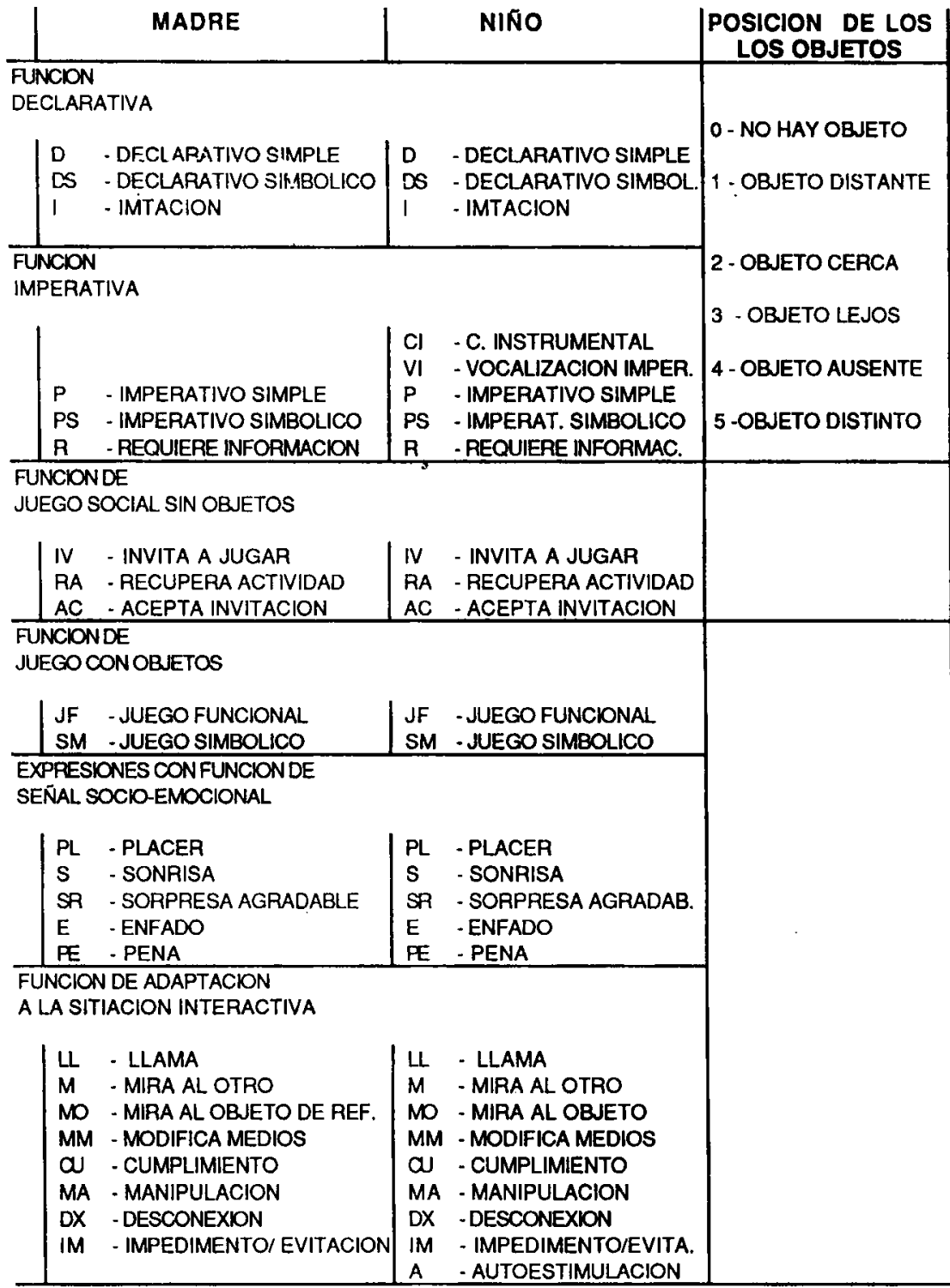

bales z-suma (Sackett, 1980), que constituyen un índice de la tendencia general del perfil de retardo.

Estos índices z-suma pueden representarse en diagramas polares. Los diagramas polares muestran relaciones de activación o inhibición entre conductas realizadas por los miembros de la interacción, y pueden tener gran valor para la descripción de la interacción.

En un gráfico de coordenadas polares, el vector (que representa la conducta) indica la intensidad de activación o inhibición respecto de la conducta tomada 
como criterio, y el ángulo que forma el vector indica su régimen global de activación e inhibición recíprocas, respecto de la conducta criterio. Así:

- Si el vector se encuentra entre $0^{\circ}$ y $90^{\circ}$ : la conducta se encuentra en el cuadrante de activación mutua. Es decir, la conducta tomada como criterio activa a la apareada, y la conducta apareada activa a la criterio cuando la apareada es considerada criterio ( $A$ activa a $B$ y $B$ activa a $A$ ).

- Si el vector se encuentra entre $90^{\circ}$ y $180^{\circ}$ : la conducta está en el cuadrante de inhibición-activación. Es decir, la conducta criterio inhibe a la conducta apareada, y la conducta apareada, considerada como criterio, activa a la conducta criterio cuando la apareada es considerada criterio ( $A$ inhibe a $B$ y $B$ activa a $A$ ).

- Si el vector se encuentra entre $180^{\circ}$ y $270^{\circ}$ : la conducta está en el cuadrante de inhibición mutua. Es decir, la conducta criterio inhibe a la conducta apareada, y la conducta apareada considerada como criterio inhibe a la conducta criterio ( $A$ inhibe a $B$ y $B$ inhibe a $A$ ).

- Si el vector se encuentra entre $270^{\circ}$ y $360^{\circ}$ : la conducta está en el cuadrante de activación-inhibición. Es decir, la conducta criterio activa a la conducta apareada, y la conducta apareada considerada como criterio inhibe a la conducta criterio ( $A$ activa a $B$ y $B$ inhibe a $A$ ).

Se aplicó un análisis secuencial completo interactivo, contando los retardos desde la primera unidad de tiempo en que ocurría la conducta criterio, y hasta la primera unidad de tiempo en que ocurría la conducta apareada (Tipo 3, subtipo 3 según Quera, 1986). Primero, se consideró criterio el subsistema y las conductas de la madre y después el subsistema y las conductas del niño. Al ser un análisis secuencial completo obtuvimos resultados de todas las conductas tomadas como criterio.

\section{RESULTADOS}

Los distintos estudios de análisis secuencial de retardo realizados para cada conducta aportaron datos sobre la relevancia de algunos actos para el comportamiento social y comunicativo. Principalmente obtuvimos resultados en los estudios secuenciales sobre el uso de y la respuesta a, conductas de mirada, imperativas, declarativas, de juego y expresiones emocionales. Teniendo en cuenta el peculiar repertorio de habilidades comunicativas de estos niños (i.e. ausencia de declarativos y presencia de imperativos), y que el propósito del presente trabajo es describir habilidades comunicativas no verbales precursoras de la capacidad metarrepresentacional, que además se muestren alteradas en los niños autistas; hemos seleccionado los estudios que aportan evidencia de alteraciones en la ejecución de estrategias de comunicación intencional no verbal. Son los estudios sobre (1) la eficacia de los actos imperativos simples ejecutados por los niños, (2) la conducta de los niños cuando sus madres les miran y (3) la conducta de los niños ante las expresiones emocionales de «sorpresa agradable» mostradas por las madres.

\section{Eficacia de los actos imperativos simples}

Los niños de nuestro estudio mostraban mayoritariamente dos tipos de conductas cuando realizaban actos imperativos no simbólicos: señalaban hacia el 
objeto deseado haciendo ocasionalmente movimientos de prensión con la mano extendida (señalar para pedir), y emitían vocalizaciones intermitentes de esfuerzo (vocalización imperativa). Los resultados del estudio de estas conductas se presentan en los gráficos de las Tablas III y IV.

La Tabla III muestra la eficacia de los niños en el uso de las conductas de señalar para pedir. En esta tabla se observa que todos los niños normales, y todos los niños S. de Down, activan el cumplimiento (CU) en la madre señalando hacia el objeto que desean, pero esto ocurre solamente en dos casos del grupo de niños autistas, a pesar de que la mayoría de los niños de este grupo mostraron actos de señalar para pedir. Es importante resaltar, además, que los tres mayores del grupo de normales parecen ser muy eficaces, porque en estos tres casos el cumplimiento de la madre inhibe el acto imperativo del niño, es decir, después de que la madre realiza el cumplimiento el niño no inicia más actos de petición.

En los casos (de cualquier grupo) en que la madre realiza actos de cumplimiento después de la petición del niño, también inicia actos comunicativos para requerir información (R). La madre requiere una información más precisa sobre un acto que posiblemente reconoce como imperativo, del que supone su contenido. Este tipo de actos realizados por la madre parecen ser un instrumento valioso a su servicio para hacer que el niño mejore en su ejecución comunicativa, y pueden compararse con los actos de «subir el listón» descritos por Wood, Bruner y Ross (1976) en el estudio de cómo las madres enseñan a sus hijos.

Varios niños normales, además de conseguir que su madre cumpla la petición, con el acto de señalar para pedir, consiguen dirigir la atención de la madre hacia el objeto, ya que la petición del niño activa en esos casos la mirada de la madre hacia el objeto de referencia (MO); en otros casos el niño señala después de que la madre mire hacia él o al objeto. Los niños $\mathrm{S}$. de Down también parecen poder dirigir la atención de la madre, o tenerla en cuenta para iniciar un acto imperativo simple. Esto sólo ocurre significativamente en un caso de los niños autistas en el que el niño señalaba para pedir después de que su madre le mirara, y conseguía el cumplimiento y la atención de la madre hacia el objeto. Ningún otro niño autista muestra relaciones funcionales significativas entre sus actos de señalar para pedir y conductas de atención de la madre. Cabe pensar que, si bien la mayoría de los autistas muestran actos imperativos, y que algunas madres de esos niños autistas pueden identificarlos como tales, realizando cumplimientos y actos de requerir información; es muy poco probable que los niños autistas con sus actos puedan manifestar una intención comunicativa, y dirigir la atención de su madre hacia el objeto de referencia con la intención de que realice un cumplimiento. El fallo de los niños autistas para conseguir objetos usando actos imperativos simples como señalar para pedir puede deberse, por tanto, a una incapacidad para dirigir o aprovechar la atención del otro hacia uno mismo o hacia un objeto manifestando un deseo.

El estudio de las vocalizaciones imperativas profundiza en este déficit comunicativo de los niños autistas (Tabla IV). Sólo dos autistas realizaron vocalizaciones en actos imperativos simples, frente a la totalidad de los niños de los otros dos grupos. En los dos casos, esos niños autistas consiguieron que su madre cumpliera la petición.

Aunque también pueden activar el cumplimiento, en todos los casos del grupo de normales y del grupo $\mathrm{S}$. de Down, las vocalizaciones imperativas del niño activan siempre el requerimiento de la madre. Es decir, es más probable que 


\section{1}

\section{TABLA III}

Casos 1, 2, y 3 (13-18 meses)

Conductas de la madre después de que el niño señala para pedir
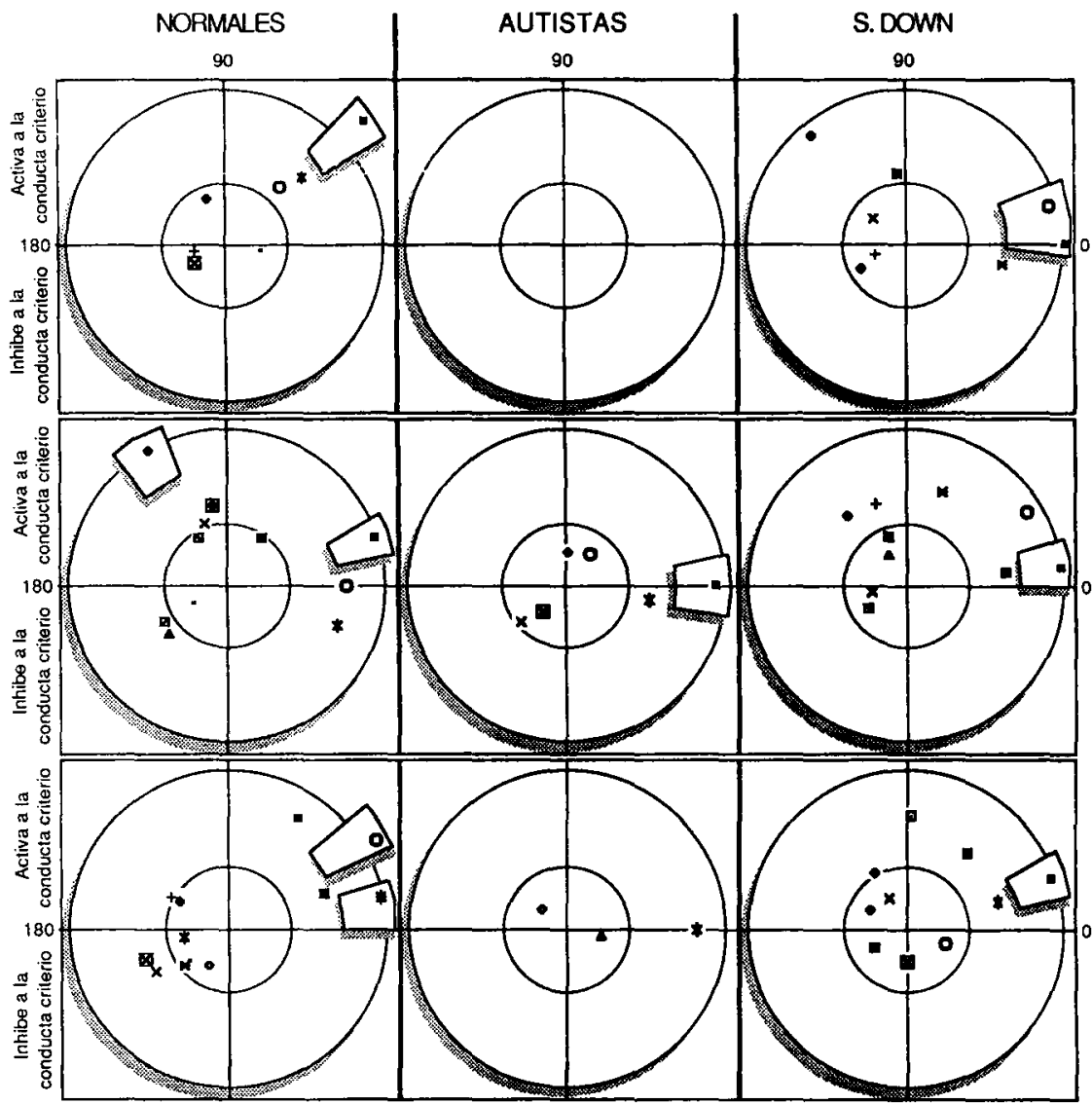

Inhibe el apareo 270 Activa el apareo Inhibe el apareo 270 Activa el apareo Inhibe el apareo 270 Activa el apareo Leyenda

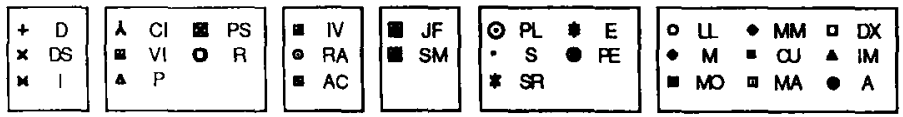

Nota:

Las conductas situadas fuera del círculo interior mantienen una relación (de activación o inhibición) con la conducta criterio significativa para $\mathrm{p}<0,05$. Las conductas representadas en semicírculos superpuestos tienen un valor z-suma superior a 5 .

la madre requiera información a que cumpla después de que el niño haya iniciado una vocalización imperativa. Puede ser que la madre active su acto de requerir información a partir el acto vocal imperativo del niño, porque trate de que el niño precise más su acto comunicativo, pero con cuidado de que el acto imperativo del niño siga siendo eficaz, por eso cumple la petición.

Como ya hemos visto, el mensaje del acto comunicativo imperativo puede ser especificado a través de un acto de señalar para pedir, que usado por los normales o los S. de Down siempre activa el cumplimiento. Puede que el acto 


\section{2}

TABLA III (Continuación)

Casos 1, 2, y 3 (13-18 meses)

Conductas de la madre después de que el niño señala para pedir

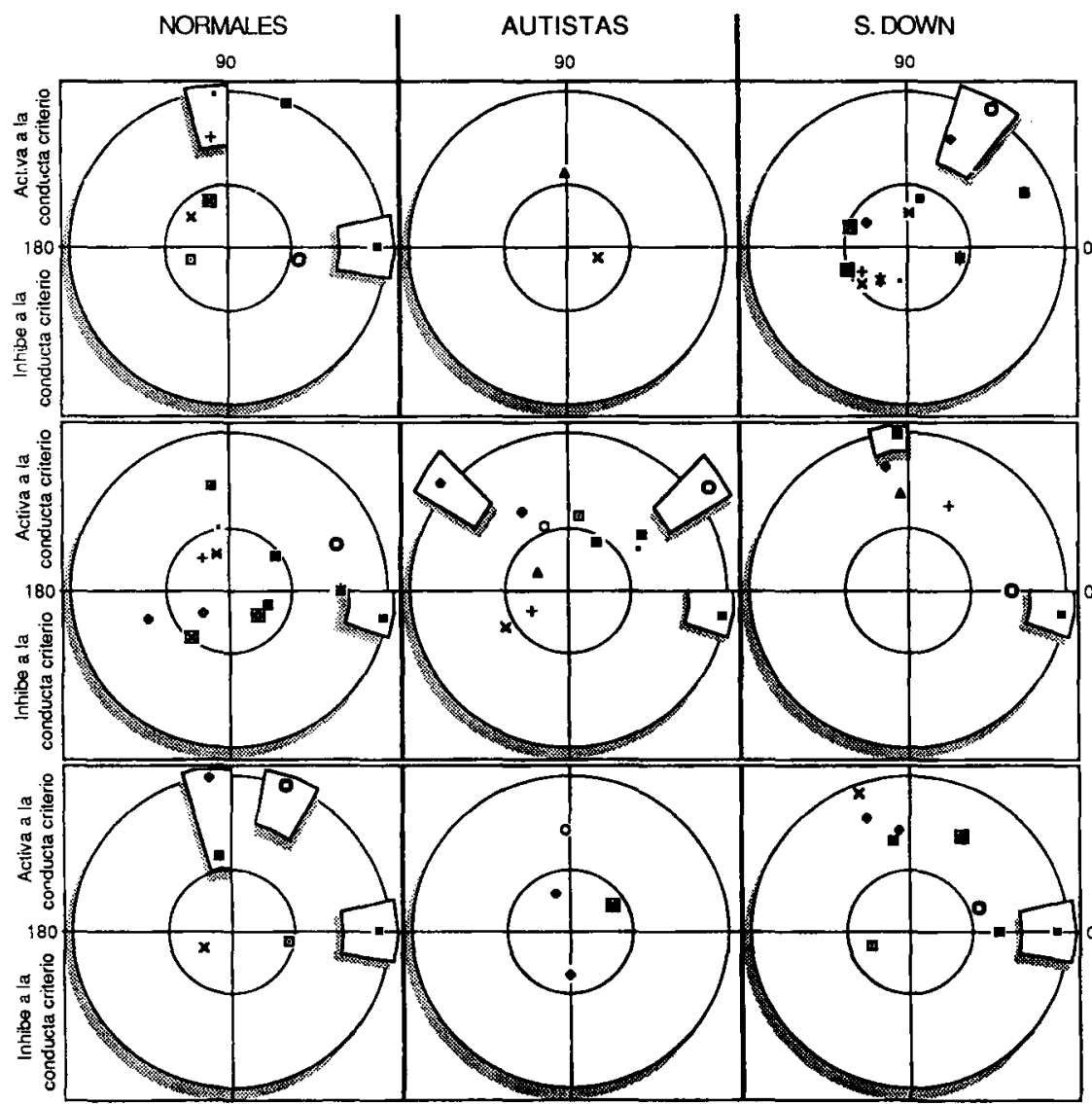

Inhibe el apareo 270 Activa el apareo Inhibe el apareo 270 Activa el apareo Inhibe el apareo 270 Activa el apareo Leyenda
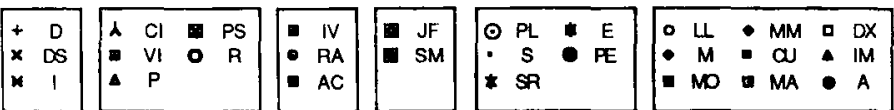

Nota:

Las conductas situadas fuera del círculo interior mantienen una relación (de activación o inhibición) con la conducta criterio significativa para $\mathrm{p}<0,05$. Las conductas representadas en semicírculos superpuestos tienen un valor $z$-suma superior a 5 .

imperativo simple de señalar para pedir, y la vocalización imperativa, aun siendo imperativos ambos, no tengan la misma función dentro del acto comunicativo del niño. El acto de señalar para pedir lleva a la madre hacia el cumplimiento del acto imperativo, mientras que la vocalización imperativa pone de manifiesto la intención del niño, dirigiendo específicamente la atención de la madre hacia el mensaje, por eso la madre requiere una información más precisa de ese mensaje. Es sobre el acto que ponen de manifiesto la intención (i.e. la vocalización 
TABLA IV

Casos 1, 2, y 3 (13-18 meses)

Conductas de la madre después de que el niño vocaliza imperativamente

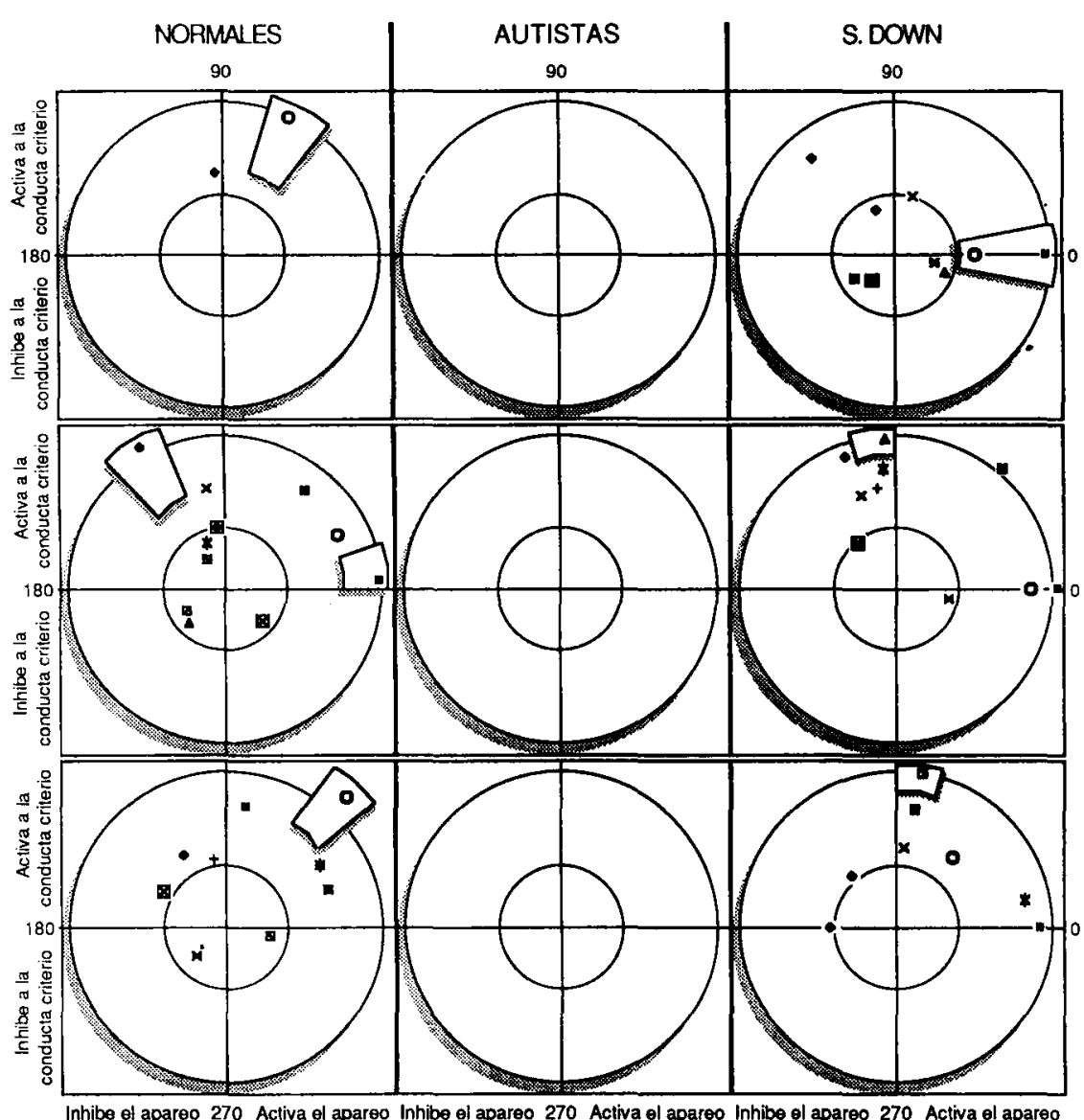

Inhibe el apareo 270 Activa el apareo Inhibe el apareo 270 Activa $\theta$ apareo inhibe $\theta$ apareo 270 Activa el apareo Leyenda
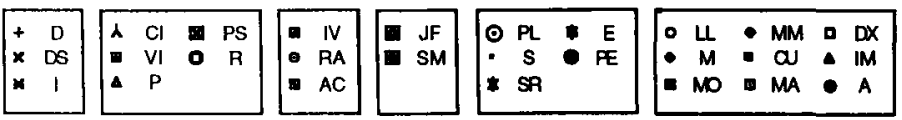

Nota:

Las conductas situadas fuera del círculo interior mantienen una relación (de activación o inhibición) con la conducta criterio significativa para $\mathrm{p}<0,05$. Las conductas representadas en semicírculos superpuestos tienen un valor $z$-suma superior a 5 .

imperativa), sobre el que la madre más frecuentemente activa sus requerimientos de información.

Según los resultados, podemos decir que los niños normales y los $\mathrm{S}$. de Down pueden conseguir más fácilmente que su madre haga cosas para ellos, usando procedimientos comunicativos más complejos que los usados por los niños autistas. Los niños normales y los $\mathrm{S}$. de Down consiguen que sus madres cumplan sus peticiones señalando hacia el objeto que desean, controlando específicamente 


\section{4}

TABLA IV (Continuación)

Casos 1, 2, y 3 (13-18 meses)

Conductas de la madre después de que el niño vocaliza imperativamente

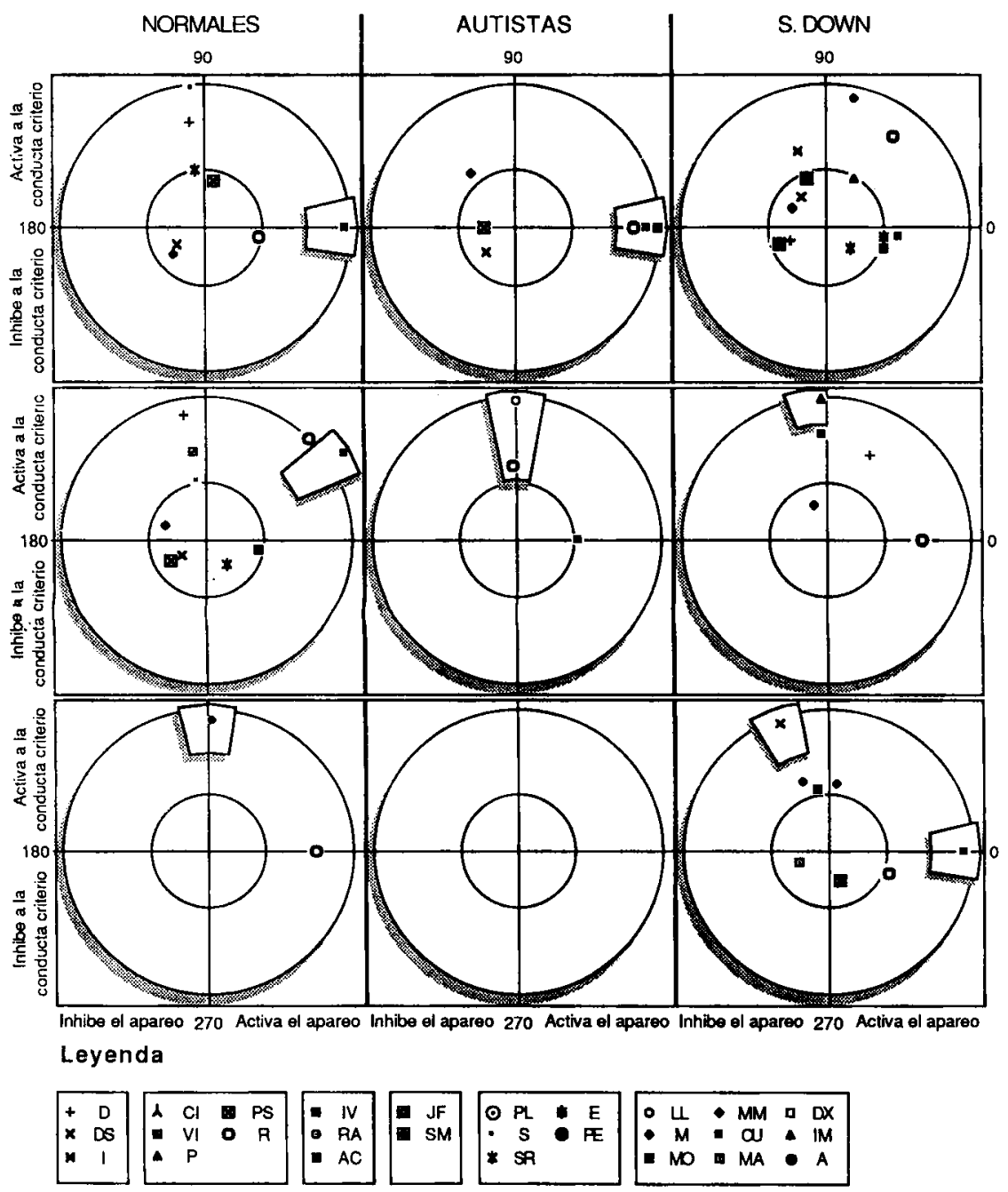

Nota:

Las conductas situadas fuera del círculo interior mantienen una relación (de activación o inhibición) con la conducta criterio significativa para $p<0,05$. Las conductas representadas en semicírculos superpuestos tienen un valor z-suma superior a 5 .

su atención por medio de vocalizaciones imperativas. Los niños autistas preverbales no suelen mostrar habilidades para controlar la atención de sus madres, como las vocalizaciones imperativas, y aunque saben señalar, generalmente no consiguen que sus madres cumplan sus peticiones.

Estos resultados pueden estar en consonancia con los obtenidos por Phillips et al. (en prensa), ya que, según parece, la estrategia comunicativa que considera la importancia de controlar y dirigir la atención es más eficaz para conseguir 
cumplimientos, y aunque algunos niños autistas consiguen que el otro realice cumplimientos, no parecen reconocer al otro como agente capaz de percibir y atender, ni utilizan una estrategia que aprecie el valor de la atención del otro para conseguir la comunicación.

\section{Conducta de los niños cuando sus madres les miran}

Los resultados de este estudio se muestran en la Tabla V. Por un lado, está claro que en los tres grupos, la mirada de la madre hacia el niño activa la mirada

\section{TABLA V}

Casos 1, 2 y 3 (13-18 meses)

Conductas del niño después de que su madre le mira

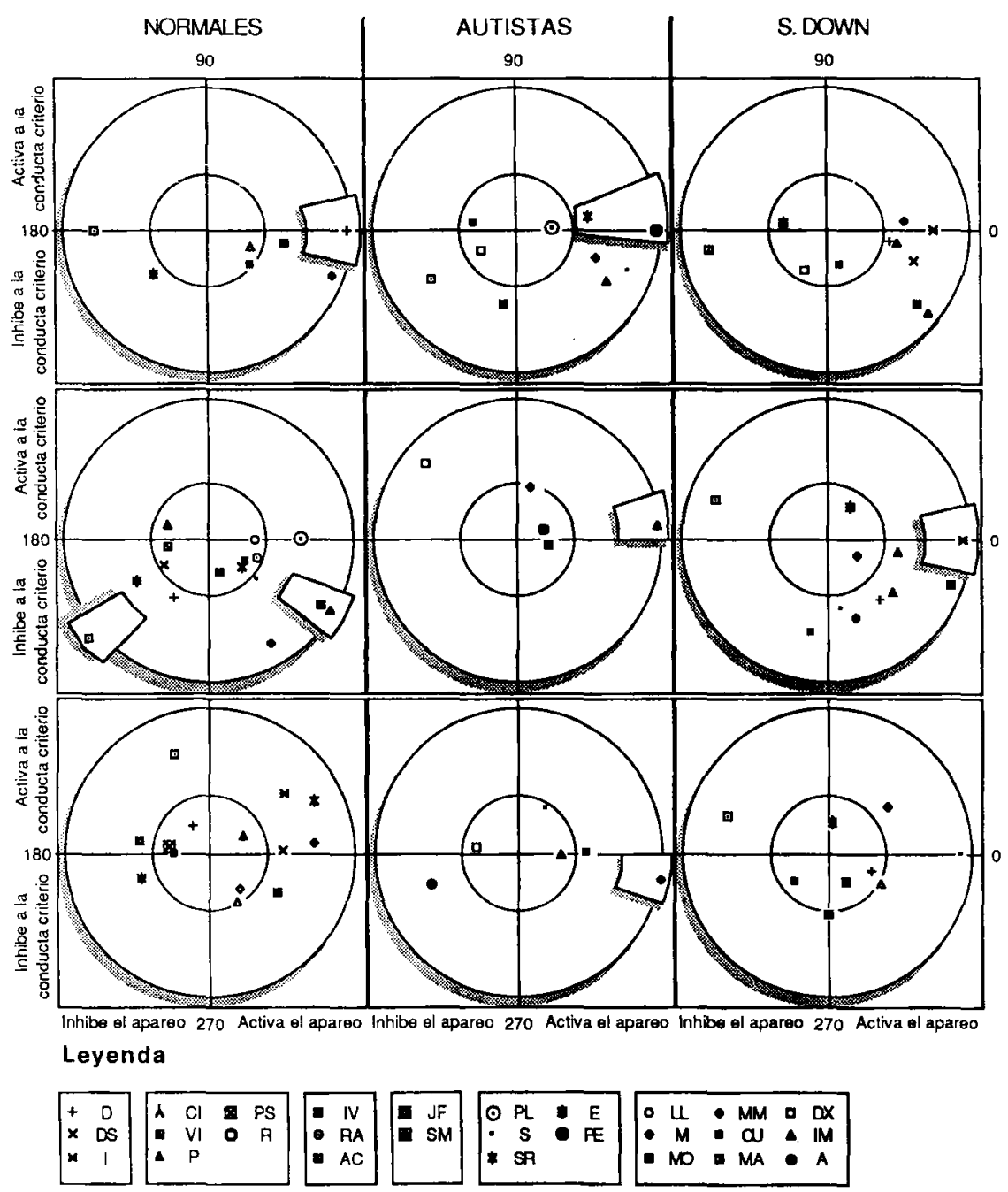

Nota:

Las conductas situadas fuera del círculo interior mantienen una relación (de activación o inhibición) con la conducta criterio significativa para $p<0,05$. Làs conductas representadas en semicírculos superpuestos tienen un valor z-suma superior a 5 . 


\section{TABLA V (Continuación)}

Casos 1, 2 y 3 (13-18 meses)

Conductas del niño después de que su madre le mira

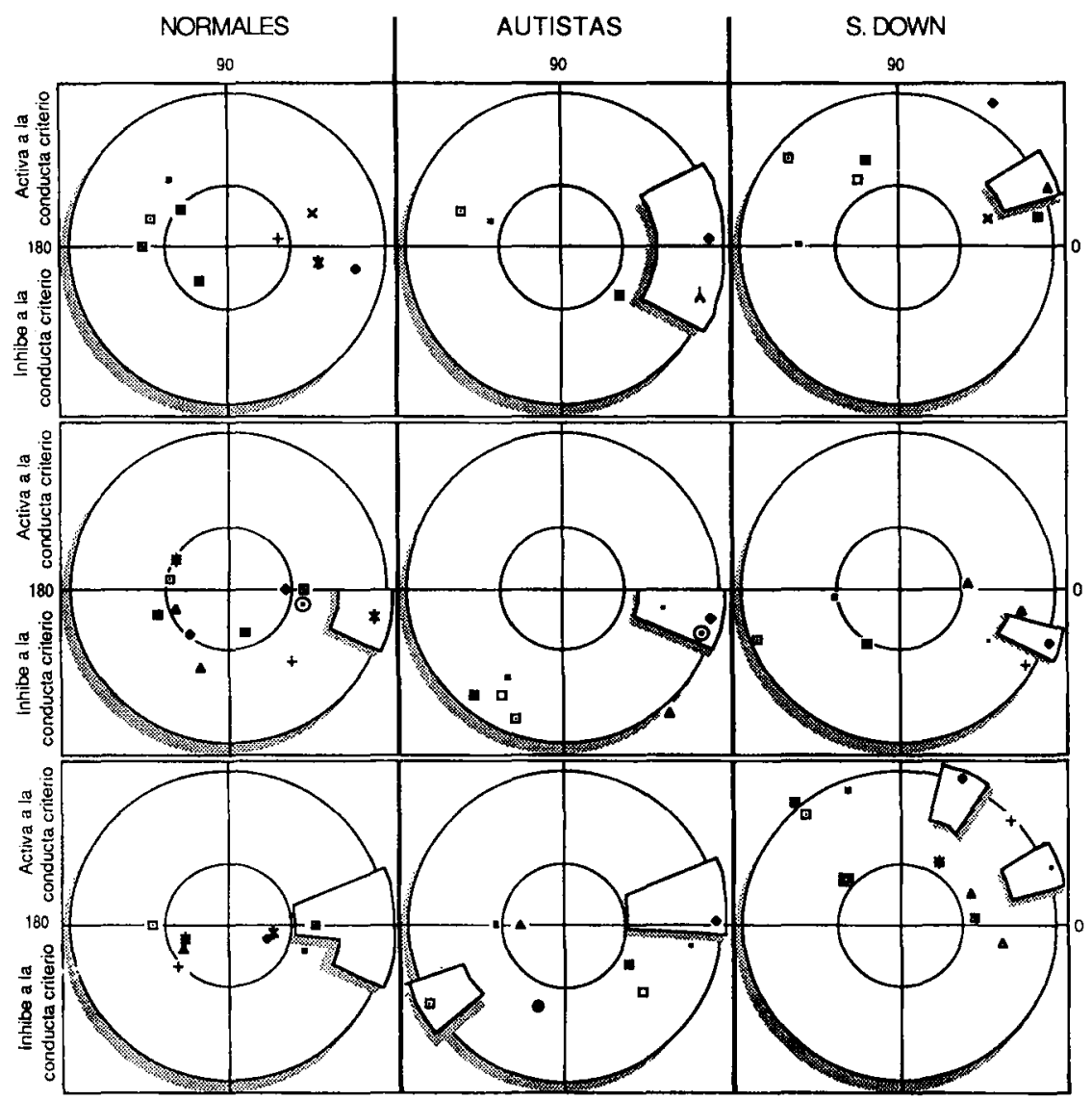

Inhibe el apareo 270 Activa el apareo Inhibe el apareo 270 Activa el apareo Inhibe el apareo 270 Activa el apareo Leyenda
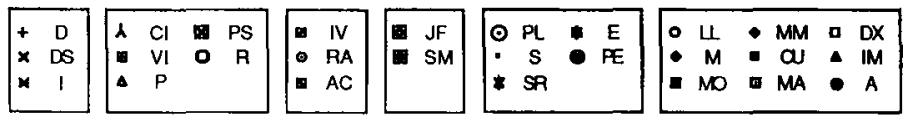

Nota:

Las conductas situadas fuera del círculo interior mantienen una relación (de activación o inhibición) con la conducta criterio significativa para $p<0,05$. Las conductas representadas en semicírculos superpuestos tienen un valor z-suma superior a 5 .

del niño hacia su madre (M), es decir, cuando la madre mira al niño, el niño mira a su madre. También en todos los casos, la mirada de la madre inhibe que los niños inicien actos de manipulación de objetos (MA); y en el grupo de los autistas inhibe, además, el inicio de otros actos no comunicativos como la autoestimulación (A) o la desconexión (DX). La inhibición de conductas no comunicativas después de que la madre mira hacia su hijo es significativa en todos los casos de todos los grupos. Por su parte, la función activadora de la mirada de 
la madre sobre la del niño es significativa en todos los casos de los tres grupos, excepto en los dos niños normales de mayor edad. Estos dos niños normales, al igual que todo su grupo, y todos los $\mathrm{S}$. de Down, después de que su madre mira hacia ellos, inician actos comunicativos imperativos o declarativos de distinto tipo. Sin embargo, sólo dos niños autistas, y sólo para la función imperativa, inician actos comunicativos no simbólicos después de que sus madres les miren. Es importante hacer notar, además, que todos los niños normales y $\mathrm{S}$. de Down muestran actos declarativos que mantienen una relación estadísticamente significativa (activadora o inhibidora) con la mirada de la madre, lo cual no se observa en ningún niño autista.

No parece, por tanto, que la característica de los niños autistas sea ausencia de mirada cuando sus madres les miran, sino ausencia de actos comunicativos específicos - como los declarativos - que se activan o inhiben, además de la mirada, como ocurre en los niños normales y en los S. de Down. En estos dos grupos vemos también que la mayoría inicia actos con función imperativa después de la mirada de sus madres hacia ellos. Sin embargo, sólo dos niños autistas muestran conductas imperativas después de la mirada de sus madres a pesar de que, como hemos visto, la mayoría de los autistas usen medios comunicativos con función imperativa. Además, sólo uno de esos dos niños autistas consigue el cumplimiento en su madre (ver Tabla III). Se puede sugerir que tanto los niños normales como los $\mathrm{S}$. de Down muestran relaciones funcionales similares entre la mirada de sus madres y sus actos comunicativos (tanto imperativos como declarativos), en otras palabras, que cuando sus madres miran hacia ellos se encuentran a un niño que las mira, y que comunica, o deja de comunicar, intenciones. Pero cuando las madres de los niños autistas miran hacia sus hijos encuentran generalmente a un niño que las mira, sí, pero que no se comunica con ellas, o si lo hace, es con una función imperativa no siempre reconocida por su madre.

Según lo expuesto, se puede decir, además, que todos los niños normales y todos los S. de Down, tienen en cuenta la atención de su madre hacia ellos para iniciar o inhibir actos comunicativos; parecen tener en cuenta la función del acceso visual para la comunicación. Es decir, pueden tener en cuenta que para que la madre sepa lo que ellos quieren o indican, es importante la atención previa hacia ellos. Para los niños normales, la mirada de la madre es una señal poderosa para iniciar actos comunicativos, lo mismo que en los niños S. de Down. Para los autistas, la mirada de la madre es, claramente, un estímulo al que atender, pero ante el cual no saben responder comunicativamente del modo que lo hacen los niños normales y los $\mathrm{S}$. de Down.

\section{Respuesta de los niños a la expresión de «sorpresa agradable» mostrada por la madre}

La conducta de los niños ante señales emocionales positivas de sorpresa se muestra en la Tabla VI. Este análisis toma como criterio la expresión de sorpresa agradable de la madre.

Se puede observar cómo la mayoría de los niños normales, sobre todo los mayores, expresan sorpresa (SR) después de que su madre haya expresado sorpresa. Esto es menos común en el grupo de los niños S. de Down, y no se da nunca en los niños autistas. Además, algunos niños normales y $\mathrm{S}$. de Down pueden expresar otras señales socio-emocionales positivas después de la sorpresa 


\section{8}

\section{TABLA VI}

Casos 1,2 y 3 (13-18 meses)

Conductas del niño después de que su madre expresa sorpresa agradable

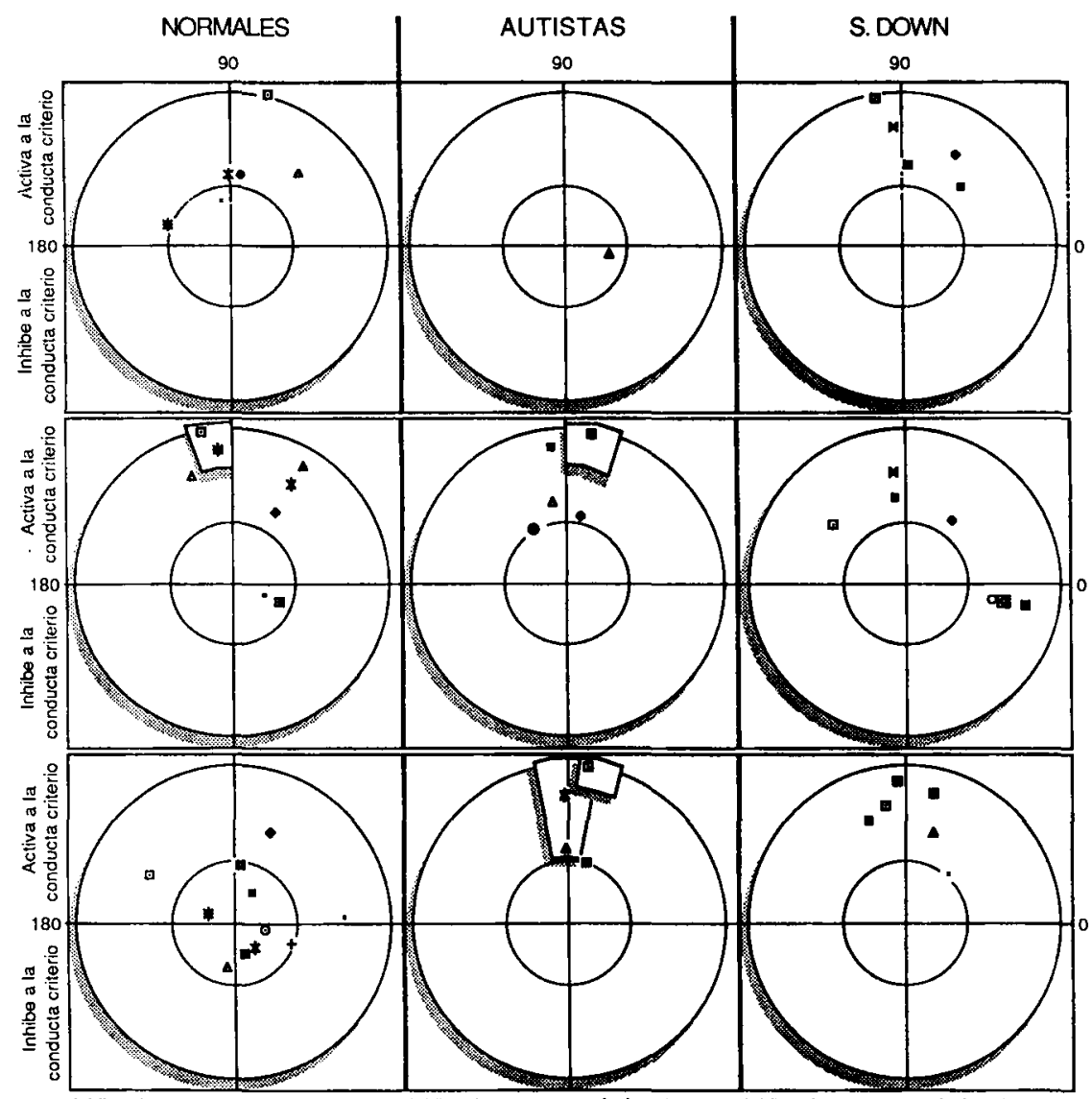

Inhibe el apareo 270 Activa el apareo Inhibe el apareo 270 Activa el apareo Inhibe el apareo 270 Activa el apareo Leyenda

$\left[\begin{array}{cc}+ & D \\ x & D S \\ M & I\end{array}\right]\left[\begin{array}{llll}A & C l & 0 & P S \\ 0 & V I & 0 & A \\ 4 & P & & \end{array}\right.$
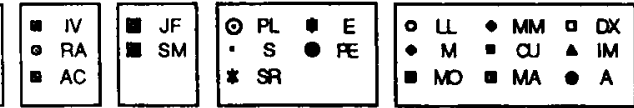

Nota:

Las conductas situadas fuera del círculo interior mantienen una relación (de activación o inhibición) con la conducta criterio significativa para $\mathrm{p}<0,05$. Las conductas representadas en semicírculos superpuestos tienen un valor $z$-suma superior a 5 .

de sus madres, como sonrisa o placer, y gran variedad de actos comunicativos y de adaptación a la situación interactiva, sobre todo de carácter positivo. Ningún niño autista mostró señales socio-emocionales positivas, o actos comunicativos, después de la expresión de sorpresa de sus madres. La respuesta de los niños autistas a las expresiones de sorpresa de sus madres parece estar, casi exclusivamente, limitada a actos como mirar a su madre o mirar a los objetos. 


\section{9}

TABLA VI (Continuación)

Casos 1,2 y 3 (13-18 meses)

Conductas del niño después de que su madre expresa sorpresa agradable
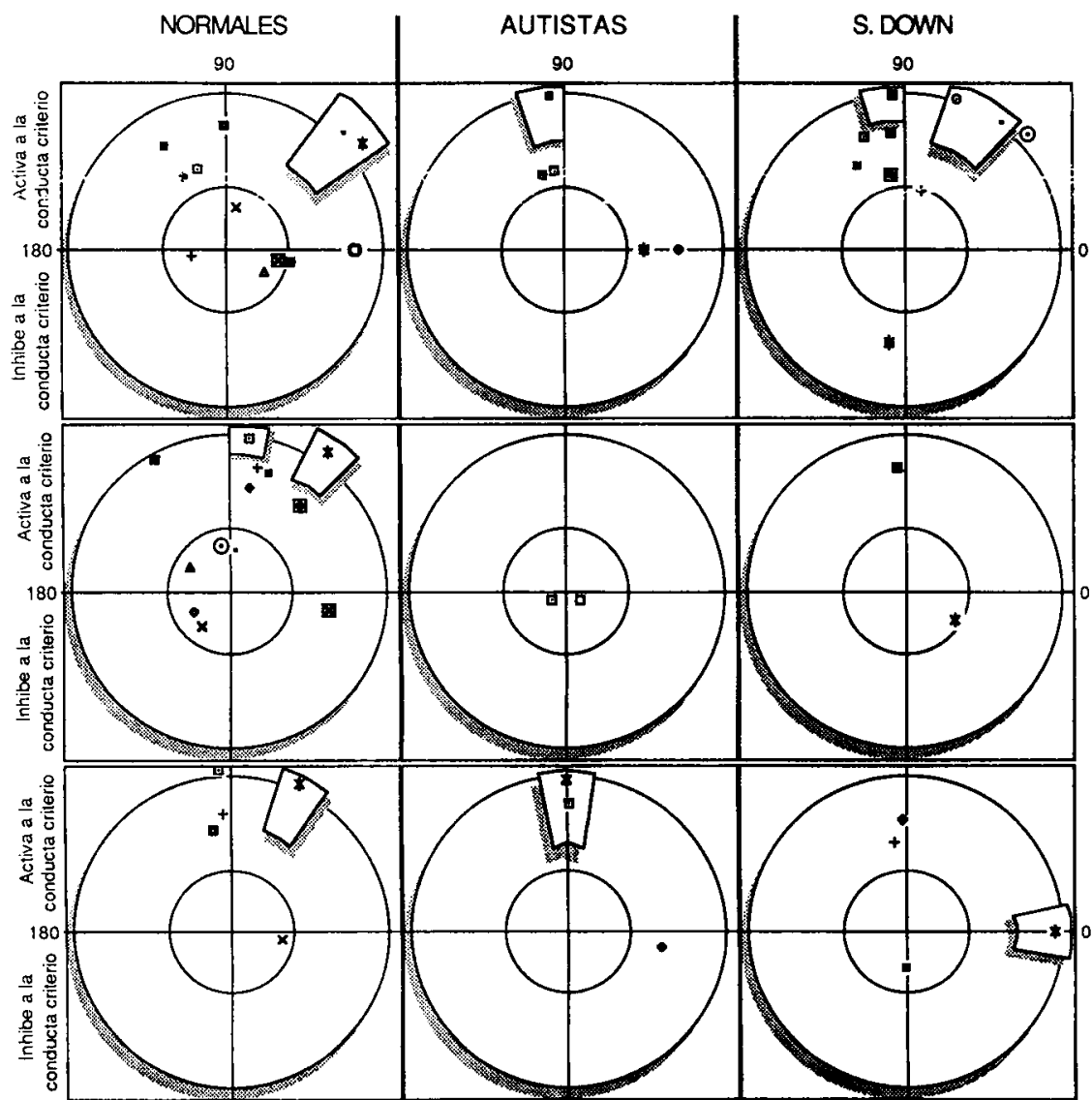

Inhibe el apareo 270 Activa el apareo Inhibe el apareo 270 Activa el apareo Inhibe el apareo 270 Activa ol apareo Leyenda
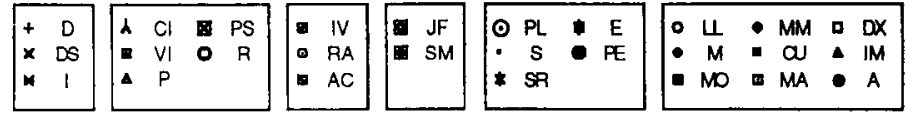

Nota:

Las conductas situadas fuera del círculo interior mantienen una relación (de activación o inhibición) con la conducta criterio significativa para $p<0,05$. Las conductas representadas en semicírculos superpuestos tienen un valor $z$-suma superior a 5 .

Según los gráficos, en los tres grupos, las manifestaciones de sorpresa de la madre parecen estar activadas, además de por la sorpresa de sus hijos, por actos de manipulación de objetos, y actos de mirada hacia la madre, o de atención hacia los objetos por parte de los niños. Es posible pensar que, con esas expresiones, la madre pretenda resaltar algún aspecto concreto relacionado con la manipulación que el niño hace de un objeto, o el propio hecho de que el niño 
la mire, o la presencia de un objeto. Los niños normales y S. de Down responden a este tipo de señales de forma muy consistente con señales de las mismas, o similares, características, pero ningún niño autista lo hace. Esto sugiere que la mayoría de los normales y algunos $\mathrm{S}$. de Down reconocen la expresión de su madre y responden a ella con un acto interactivo, que, como señal, es similar a la que sus respectivas madres han emitido previamente. Cuando el niño también expresa sorpresa compartirá con su madre una experiencia emocional positiva respecto a algo. Esto es lo que no hace ningún niño autista.

También otras conductas sociales y/o comunicativas de los niños activan las expresiones de sorpresa en sus madres. En los menores de 18 meses las más frecuentes son los actos de señalar para pedir, y las imitaciones. Las habilidades de imitación y el incipiente dominio de la referencia con intención imperativa parece sorprenderlas positivamente, aunque quizá los actos de los niños no tengan intención de provocar dicha expresión en sus madres. Por otro lado, en ningún caso de los niños mayores de 18 meses, la madre expresó sorpresa ante los actos imperativos de sus hijos. Lo que se observa más frecuentemente, pero sólo en los sujetos normales y S. de Down mayores de 18 meses, es una relación de activación entre conductas declarativas simples del niño y expresiones de sorpresa en la madre. Es en estos casos donde, también con más frecuencia, se puede observar que los niños responden sistemáticamente con sorpresa a las expresiones de sorpresa de las madres.

Los niños normales y S. de Down mayores de 18 meses buscan con los declarativos simples - cuyo predicado es prestar atención- compartir con sus madres una experiencia sobre el objeto o evento. La madre puede reconocer esa intención de su hijo mostrando una señal socio-emocional positiva, como es la expresión de sorpresa agradable. A su vez, estos niños reconocen esa expresión como señal, ya que responden a ella con una expresión de similares características. Podemos pensar que los niños normales y S. de Down, que usan declarativos simples capaces de activar expresiones de sorpresa en sus madres, y que responden con señales socio-emocionales positivas a la expresión de la madre, están reconociendo que sus madres comparten el motivo que ellos querían mostrar. Pero esto no implica que el objetivo del niño sea obtener la expresión emocional de su madre, sino que el niño reconoce a través de tal señal que el objetivo de su acto comunicativo se ha cumplido.

Las expresiones de sorpresa agradable pueden ser vistas como señales socioemocionales que sirven para indicar que se comparte una experiencia relacionada con la acción manipulativa, social o comunicativa del momento. Una señal que indica que el suceso o el mensaje ha sido experimentado (o «sentido») por el otro. Si esto es así, los niños autistas carecen de la habilidad para reconocer que el otro comparte una experiencia similar a la propia.

\section{CONCLUSIONES}

Los resultados que acabamos de exponer describen claramente algunas diferencias funcionales en el repertorio comunicativo de un grupo de niños autistas, respecto de niños normales y S. de Down. Por ello, podemos afirmar que esta metodología se ha mostrado pertinente para poner en evidencia las diferencias en comunicación no verbal entre estos tres grupos. Esta descripción del comportamiento comunicativo informa principalmente de que los niños autis- 
tas carecen de ciertas habilidades comunicativas y sociales que pueden ser relevantes para el desarrollo de la comunicación.

El estudio de las conductas imperativas realizadas por los niños resalta que los niños autistas se muestran ineficaces en el intento de dirigir la atención y la acción de sus madres para que cumplan un deseo previo del niño.

Los actos de señalar para pedir por sí solos pueden ser eficaces, porque activan generalmente los cumplimientos. Pero cuando los niños normales y los S. de Down los realizaban disponían previamente de la atención específica de su madre hacia ellos, y/o la dirigían después de iniciar el acto gestual. Esto sólo ocurrió en un caso de los niños autistas. Esta diferencia puede deberse a que mientras todos los normales y S. de Down utilizaron vocalizaciones imperativas, sólo dos autistas mostraron este tipo de actos. El hecho de disponer de la atención del otro antes de iniciar un acto imperativo puede no ser suficiente, puesto que los actos imperativos eficaces deben activar conductas específicas de atención y de acción hacia el actor y hacia el objeto independientemente de si el otro ya estaba, o no, mirando previamente.

La vocalización imperativa del niño puede tener esa función especializada en la tarea de dirigir la atención del otro, porque aunque no siempre activa el cumplimiento, siempre hace que la madre se dirija al niño con actos para requerir información sobre su acto comunicativo. Gracias a la vocalización imperativa, las madres de los niños normales y S. de Down pueden prestar atención a su hijo, atribuyéndole una intención comunicativa de tipo imperativo, a través de actos de requerir información. La vocalización imperativa sitúa una acción propia del niño en el entorno de la otra persona, y pone de manifiesto la intención del actor de que el otro «haga algo», que, en los normales y en los $\mathrm{S}$. de Down se especifica muy eficazmente por medio del acto de señalar.

Esta diferenciación funcional entre los actos de señalar para pedir y las vocalizaciones imperativas puede ser de gran importancia para el desarrollo de la comunicación. Mientras los actos de señalar para pedir, mostrados por los normales y los S. de Down, dirigen la atención hacia el objeto de referencia y son más eficaces para conseguir los cumplimientos, las vocalizaciones imperativas permiten atribuir una intención de tipo imperativo, dando lugar a requerimientos más que a cumplimientos. Por eso, pueden ser vistas como una manifestación temprana de la habilidad para mostrar estados mentales de deseo. En este sentido podría considerarse que el uso de la vocalización imperativa es una habilidad precursora para incorporar la capacidad metarrepresentacional en la comunicación, ausente en la mayoría de los niños autistas.

$\mathrm{El}$ análisis de la conducta del niño a partir de que su madre empiece a mirarle nos permitió saltarnos la necesidad de que el niño tuviera que usar una estrategia previa de "control de la atención del otro». Si el fallo de los autistas residiera simplemente en que sus actos comunicativos no sirven como estrategia para controlar la atención del otro, en este análisis veríamos que pueden mostrar actos comunicativos aprovechando que el otro les mira. Pero no es así. Mientras los niños normales y los $\mathrm{S}$. de Down aprovechan la mirada de sus madres para iniciar gran variedad de actos comunicativos, los niños autistas mayoritariamente sólo miran a su madres después de que ésta les mire, a pesar de que en su repertorio muestren actos comunicativos de tipo imperativo. El fallo de los niños autistas en el uso de actos comunicativos de tipo imperativo puede deberse no sólo a la dificultad para poner de manifiesto intenciones, como ya hemos dicho, sino también a una dificultad para tener en cuenta la atención 
del otro hacia ellos como señal que indica el momento más adecuado de iniciar un acto comunicativo. Esta segunda dificultad podría considerarse como una prueba más del déficit pragmático que caracteriza a los niños autistas no verbales.

Finalmente, en cuanto a la respuesta de los niños a la expresión de sorpresa agradable, ningún niño autista mostró señales socio-emocionales positivas, o actos comunicativos, cuando su madres mostraba sorpresa agradable. La respuesta de los niños autistas a las expresiones de sorpresa de sus madres parece consistir solamente en actos como mirarla a ella o mirar a los objetos. En cambio, la mayoría de los niños normales y algunos $\mathrm{S}$. de Down, sobre todo los mayores, expresan sorpresa después de que su madre haya expresado sorpresa. Además, algunos niños normales y $\mathrm{S}$. de Down muestran otras señales socio-emocionales positivas después de la sorpresa de sus madres, como sonrisa o placer, y gran variedad de actos comunicativos y de adaptación a la situación interactiva de carácter positivo.

Si con estas expresiones la madre pretende indicar que comparte la emoción que le produce algún objeto o suceso, parece que lo consigue si el niño es normal o S. de Down, ya que estos responden a esas señales de forma muy consistente con señales de características similares. Pero ningún niño autista lo hace. Esto sugiere que los autistas carecen de mecanismos que les permiten apreciar esas señales emocionales como señales de que el otro comparte una experiencia referente a un suceso $\mathrm{u}$ objeto.

La idea de que cuando el niño responde con sorpresa, madre e hijo comparten una experiencia emocional se sustenta no sólo por la activación mutua de la expresión, sino también por los casos en que hay una asociación activadora entre sorpresa de la madre y declarativos simples del niño. En esos casos, el niño con su acto declarativo simple posiblemente predica: «quiero que atiendas a lo que yo atiendo» y la madre con su expresión de sorpresa indica (positivamente) que comparte esa experiencia respecto de lo que llama la atención al niño. Al responder los niños con la misma expresión mostrada por la madre, podrían estar reconociento el acto de sus madres como señal de que ella también comparte esa experiencia.

La activación mutua de expresiones de sorpresa, por tanto, podría verse como una habilidad temprana, útil para la estrategia de compartir experiencias personales producidas por sucesos u objetos. En este sentido el reconocimiento y el uso de expresiones emocionales de sorpresa agradable dentro del intercambio comunicativo y social podría considerarse una habilidad precursora para usar la capacidad metarrepresentacional en la comunicación. Dicha habilidad estaría ausente en el repertorio comunicativo de los niños autistas preverbales.

En resumen, según nuestros resultados, apoyamos la idea de que en el problema comunicativo de los niños autistas no verbales influyen factores sociocognitivos, como la alteración en el uso de habilidades imperativas y el déficit pragmático para aprovechar la atención del otro, y factores socio-afectivos, como la ausencia de respuesta emocional positiva a las expresiones de sorpresa agradable mostradas por los demás. Sugerimos que estos problemas podrían afectar al desarrollo de habilidades precursoras para incorporar la capacidad metarrepresentacional a la comunicación. 


\section{Notas}

1 Siguiendo a Bruner y Sherwood (1983), Mundy et al. clasifican las habilidades no verbales de comunicación en tres categorías o funciones: conductas de "afiliación», que consisten en el uso de procedimientos no verbales para elicitar o mantener la interación cara a cara (ej. un juego de toma de turnos); conductas de «petición» o «regulación» que consisten en el uso de procedimientos para obtener la ayuda de otra persona para conseguir objetos o eventos (ej. hacer intentos de alcanzar un objeto); y conductas de «atención conjunta» o «indicación» que consisten en el uso de procedimientos para coordinar la atención entre los participantes de una interacción para compartir un conocimiento sobre objetos o eventos. (Ej. mostrar un juguete, o alternar la mirada entre un objeto y el otro participante).

2 La capacidad para atribuir estados mentales consiste en una operación inferencial mediante la cual una persona se representa a sí misma el estado mental de otra persona, es decir lo que otra persona piensa, imagina, cree, etc.; esa representación que uno hace sobre la representación mental de otra persona es una representación de segundo orden o metarrepresentación (Leslie, 1987). También se ha denominado «Teoría de la Mente» (Premack y Woodruff, 1978), puesto que implica que una persona postula la existencia de estados mentales en otros, y los usa para comunicarse o establecer relaciones sociales con los demás.

\section{Referencias}

ANGUeRA, M. T. (1985). Establecimiento de pautas para la viabilidad en la categorización y reducción de datos en la transformación de marcos de conducta. Memoria presentada en la Oposición a Cátedra de la U. de Barcelona.

Anguern. M. T. (1988). Metodología en el Análisis Secuencial de Retardo. Conferencia presentada en la U. Pontificia de Salamanca. Febrero de 1988.

American Psychiatric Association: DSM-III-R (1987). Versión castellana: DSM IIIR. Manual de diagnóstico y estadístico de los trastornos mentales. Barcelona: Masson.

Attwood. A.; Frith. U., y Hermelin, B. (1988). The understanding and use of interpersonal gestures by autistic and Down's syndrome children. Joumal of Autism and Developmental Disorders, 18, 241-257.

BAKEMAN, R., y ADAMSON, L. B. (1984). Coordinating attention to people and objets in mother-infant and peer-infant interaction. Child Development, 55, 1.278-1.289.

BARON.COHEN, S. (1989a). The autistic child's theory of mind: a case of specific developmental delay. Journal of Child Psychology and Psychiatry, 30, 285-297.

Baron.Colen, S. (1989b). Perceptual role taking and protodeclarative pointing in autism. British Journal of Developmental Psychology, 7, 113-127.

Baron-Cohen, S.; Leslie, A. M.; Frith, U. (1985). Does the autistic child have a «theory of mind»? Cognition, 21, 37-46.

Baron.Cohen, S.; Leslie, A. M.; Frith, U. (1986). Mechanical, behavioural and intentional understanding of picture stories in autistic children. British Journal of Developmental Psychology, 4, 113-125.

Canal. R. (1991). Cognición y afecto desde la perspectiva del análisis interactivo. Ponencia presentada en el VI Congreso Nacional de Autismo y Psicosis Infantiles. Mallorca.

Curcio, F. (1978). Sensoriomotor functioning and communication in mute autistic children. Journal of Autism and Childbood Schizopbrenia, 8, 281-292.

FriTI, U. (1989). Autism. Explaining the Enigma. Basil Blackwell. Oxford (Trad. cast. ed. Alian2a, 1991).

Homsun. R. P. (1986a). The autistic child's apprasial of expressions of emotion. Joumal o Cbild Psycbology and Psychiatry, 27, 321-342.

Horson. R. P. (1986b). The autistic child's apprasial of expressions of emotion. A further study. Journal of Child Psychology and Psychatry, 27, 671-680.

Hunson. R. P.; Outson, J., y LEE, A. (1988a). What's in face? The case of autism. British Journal of Psychology, 79, 441-453

Hobson, R. P.; Outson, J., y Lee, A. (1988b). Emotion recognition in autism: coordinating faces and voices. Psychological Medicine, 18, 911-923.

Kanner, L. (1943). Autistic disturbances of affective contact. Nervous Child, 2, 217-250.

Kasari. C.; Sigman. M.; Mundy, P., y Yirmiyn. N. (en prensa). Affective sharing in the context of joint attention interactions of normal, autistic and mentally retarded children. Joumal of Autism and Developmental Disabilities.

Lestue. A. M. (1987). Pretense and representation: The origins of «theory of mind». Psychological Review, 94, 412-426.

Leslie. A. M., y Happé, F. (1989). Autism and Ostensive communication: The relevance of metarepresentation. Development and Psychopatology. 
Leslue, A. M., y Frith, U. (1990). Prospects for a cognitive neuropsychology of autism: Hobson's choice. Psychological Review.

LovelAND, K., y LANDRY, S. (1986). Joint attention in autistic and language delayed children. Journal of Autism and Developmental Disorders, 16, 335-350.

Mundy, P., y Sigman, M. (en prensa). The theoretical implications of joint attention deficits in autism. Development and Psychopathology.

Mundy, P.; Sigman, M.; Ungerer, J., y Sherman, T. (1986). Defining the social deficits in autism: The contribution of non-verbal communication measures. Joumal of Child Psychology and Psychiatry, 27, 657-669.

Mundy, P.; Sigman, M.; Ungerer, J., y Sherman, T. (1987). Nonverbal communication and play correlates of language development in autistic children. Joumal of Autism and Developmental Disorders, $17,349-364$.

Mundy, P., y Sigman, M. (1989). Specifing the nature of the social impairment in autism. En Dawnson, G. (Ed.). Autism. Nature, Diagnosis, and Treatment. Nueva York. The Guilford Press.

Perner, J.; Frith, U.; Leslie, A. M., y Leekam, S. R. (1989). Exploration of the autistic child's theory of mind: Knowledge, belief and communication. Child Development, 60. 689-700.

Phillips, W.; LaA, V.; Gómez, J. C.; Baron-Cohen, S., y Rrvière, A. (en prensa). Treating people as objets, agents or subjets: What can we learn from the Muni task about development and autism.

Quera, V. (1986). Microanálisis de la conducta interactiva: una aplicación a la interacción maternofilial en chimpancés. Tesis Doctoral inédita presentada en la U. de Barcelona.

Rivière, A. (1990). Origen y desarrollo de la función simbólica en el niño. En J. Palacios, A. Marchesi y C. Coll (Eds.). Desarrollo psicológico y educación, I. Psicología evolutiva (113-130). Alianza Psicología. Madrid.

SACKетт, G. P. (1978). «Measurement in observational research. En Sackett, G. P. (Ed.). Observing bebavior. Vol II: Data collection and analysis methods. Baltimor: University Park Press.

SACKETT, G. P. (1980). «Lag sequential analysis as a data reduction technique in social interaction research». En D. Sawin, R. C. Hawkins, L. O. Walker y J. H. Penticuff (Eds.). Exceptional infant. Psychosocial risks in infant-envirotment transactions. Vol. 2, 300-340. Nueva York. Brunner-Mazel.

SCHAFfer. H. R. (1977). Studies in mother-infant interaction. Academic Press. Londres.

SCHAFFER, H. R. (1984). Interacción y socialización. Madrid: Visor.

Premack, D., y Woodruff, C. (1972). Does the chimpanzee have a theory of mind? The Behavioral and Brain Sciences, $1,515.526$.

Trevarthen, C. (1982). The primary motives for cooperative understanding. En G. H. Butterworth y P. Light (Eds.). Social cognition. Studies in the development of understanding. Brighton: Harvester Press.

WERNER, H., y KAPLAN, B. (1963). Symbol formation. Nueva York: Wiley.

Wetherby, A. M., y Prutting, C. (1984). Profiles of communicative and cognitive-social abilities in autistic children. Seminars in Speech and Language.

WoOd, D.; Bruner, J., y Ross, G. (1976). The role of tutoring in problem solving. Joumal of Child Psychology and Psychiatry, 17, 89-100.

Yirmiya, N.; Kasari, C.; Sigman, M., y Mundy, P. (1989). Facial expresions of affect in autistic mentally retarded and normal children. Joumal of Child Psychology and Psychiatry, 30, N. ${ }^{\circ} 5,725-735$. 